\title{
O CONSUMO E O CRÉDITO NA SOCIEDADE CONTEMPORÂNEA
}

Filipa Ramos Moreira ${ }^{1}$

Resumo: A sociedade capitalista conduziu, por um lado, à democratização do consumo e, por outro, ao constante aparecimento de novas e complexas necessidades. $O$ ato de consumir deixou, por isso, de servir unicamente para satisfazer uma necessidade individual, para passar a responder a uma necessidade social: mostrar aos outros o grupo ou a classe social ao qual se pertence.

Associado a este crescimento do consumo, assistiu-se ao aumento do recurso ao crédito para o financiar. Este artigo aborda o conceito de consumo, quer em termos económicos quer em termos sociais, e mostra como o crédito veio permitir que os indivíduos ajustassem o seu rendimento às suas despesas, financiando-lhes a aquisição de uma vasta gama de bens e serviços. O crédito melhorou o conforto e a qualidade de vida, ao permitir satisfazer as necessidades pessoais e sociais dos indivíduos.

Palavras-chave: necessidade, consumo, crédito

\begin{abstract}
Capitalist society led, on the one hand, to the democratization of consumption and, by another, to the constant emergence of new and complex necessities. Therefore, the act of consumption is used not only to satisfy an individual necessity but also to answer a social necessity: to show the others the social group or social class to which someone belongs.

This growth in consumption led to the increase of the use of credit to fund it. This article discusses the concept of consumption, both in economic and social terms, and shows how credit has allowed individuals to adjust their incomes to their expenditure by financing them the acquisition of a wide range of goods and services. Credit has improved the comfort and the quality of life, when allowing the satisfaction of personal and social necessity of the individuals.
\end{abstract}

Keywords: necessity, consumption, credit

\footnotetext{
${ }^{1}$ Departamento de Economia, Gestão e Ciências Sociais - Centro Regional das Beiras da Universidade Católica Portuguesa. E-mail: filiparamosmoreira@gmail.com
} 


\section{Filipa Ramos Moreira}

\section{INTRODUÇÃO}

Neste artigo pretende-se primeiro analisar o conceito de consumo na sociedade contemporânea, para depois se desenvolver a consequente evolução do crédito. Começa-se por privilegiar a perspetiva económica do consumo, quer micro quer macroeconómica. No entanto, como o consumo não tem apenas uma função utilitária ou de análise micro ou macroeconómica, salienta-se, de seguida o seu significado social. O desenvolvimento da sociedade ao longo da história foi tornando cada vez mais difícil o processo de tomada de decisão. $\mathrm{O}$ ato de consumir deixou, por isso, de servir unicamente para satisfazer uma necessidade individual, para passar a responder a uma necessidade social: mostrar aos outros o grupo ou a classe social ao qual se pertence.

Associado a este crescimento do consumo, assistiu-se ao aumento do recurso ao crédito para o financiar. A necessidade de apresentar uma imagem e um estilo de vida semelhante ao do grupo de referência social, levou a um grande crescimento da procura de crédito ao consumo, uma vez que o crédito veio permitir que os indivíduos ajustassem o seu rendimento às suas despesas, financiando-lhes a aquisição de uma vasta gama de bens e serviços. O crescimento continuado das taxas de endividamento das famílias verificado na maioria dos países da Europa e nos EUA nas últimas décadas, permite concluir que o crédito ao consumo se expandiu a todas as classes sociais, deixando de ser apenas concedido às classes favorecidas ou de ser visto como um sinal de pobreza. $\mathrm{O}$ crédito melhorou o conforto e a qualidade de vida, ao permitir satisfazer as necessidades pessoais e sociais dos indivíduos. A crise financeira, que se vive atualmente, pode ser precisamente explicada em parte pelo aumento descontrolado do recurso ao crédito para obtenção de bens, de modo a suprimir necessidades essenciais e a mostrar sinais de status para os outros.

Em Portugal, foi a partir da década de noventa que o crédito ao consumo registou um grande crescimento, apoiado no processo de desregulamentação e na liberalização do sistema bancário nacional, na descida das taxas de juro e da taxa de inflação, em consequência do processo de adesão à União Económica e Monetária e à entrada na Zona Euro, e na eliminação de políticas de limites de crédito, o que se refletiu positivamente sobre a oferta de crédito, criando as condições para o aparecimento de novos produtos e conduzindo a uma maior facilidade no acesso ao crédito. Para além disso, o baixo nível de endividamento das famílias portuguesas, a manipulação das campanhas publicitárias para a concessão de crédito ao consumo e a existência de menores custos de transação devido ao rápido desenvolvimento tecnológico, contribuiu 
igualmente para o rápido crescimento da procura de crédito, colidindo com valores tradicionais contraditórios bem enraizados na sociedade portuguesa. Num momento de conjuntura económica favorável, a publicidade transmitiu a ideia de que os créditos não eram caros, camuflando os verdadeiros custos dos empréstimos e destacando a sua facilidade de contratação.

\section{A ECONOMIA DO CONSUMO}

O conceito de consumo assume uma grande variedade de significados, de acordo com o enquadramento teórico à luz do qual é formulado. Privilegiando a perspetiva económica de consumo, aquela que aqui se pretende desenvolver, o consumo é entendido como um ato económico na medida em que permite adquirir bens e serviços que satisfazem as necessidades humanas (finalidade última da atividade produtiva). É por isso toda a atividade que envolve a seleção, compra, uso, manutenção, reparação e destruição de um qualquer produto ou serviço (Campbell, 1995, p. 102).

$\mathrm{Na}$ abordagem microeconómica do consumo, trata-se o consumo sobretudo como uma escolha individual e utilitária, na convicção de que, estando o consumidor ciente dos custos e benefícios inerentes às escolhas que estão à sua disposição, optará por aquela que lhe trará maior benefício. Tendo em conta o princípio da escassez, constata-se que embora os nossos recursos sejam finitos, o nosso desejo por bens e serviços é tendencialmente insaciável ${ }^{2}$. O grande desafio é fazer uso dos nossos recursos limitados de forma a satisfazer o mais possível os nossos desejos, isto é, de forma a maximizar a utilidade esperada do consumidor.

A utilidade é um conceito de base na teoria do consumidor, proposta pelos economistas utilitaristas, e representa o grau de satisfação ou prazer que os consumidores atribuem aos bens e serviços que podem adquirir no mercado $^{3}$ (Samuelson \& Nordhaus, 1993). Explica de que forma os consumidores racionais dividem os seus recursos escassos entre as alternativas que lhes proporcionam satisfação. Jeremy Bentham e John

\footnotetext{
${ }^{2}$ O Princípio da Escassez diz-nos que os bens são escassos porque não há recursos suficientes para produzir todos os bens que as pessoas desejam ter.

${ }^{3} \mathrm{O}$ utilitarismo é uma teoria normativa, com origem nas obras dos filósofos e economistas Jeremy Bentham e John Stuart Mill, segundo a qual uma ação é moralmente correta se maximizar a felicidade, considerada não apenas a felicidade do agente da ação mas também a de todos os afetados por ela, uma vez que os indivíduos não deveriam ter apenas em conta o seu interesse próprio. Assim, o prazer ou a felicidade é o fim último da ação, e a ação moral tem de procurar maximizar, imparcialmente, a felicidade de todos. Esta teoria vigorou durante o século XVIII e princípios do século XIX.
} 


\section{Filipa Ramos Moreira}

Stuart Mill referem que a felicidade está na aquisição daquilo que nos é útil. O útil, de um modo geral, leva à satisfação, ao prazer e ao bem-estar. Mais tarde, outra corrente económica, os marginalistas, explicaram a tomada de decisão através do equilíbrio dos gastos marginais com os ganhos marginais, evidenciando que os desejos de cada indivíduo envolviam a escolha na margem ${ }^{4}$. A utilidade marginal é o acréscimo de utilidade que se verifica quando é consumida mais uma unidade do bem. Enquanto não é atingida a saciedade, a utilidade marginal é sempre positiva, ou seja, existirá sempre algum acréscimo de utilidade quando é consumida mais uma unidade do bem. Contudo, devido à lei da utilidade marginal decrescente, à medida que se consome mais de um bem, a utilidade adicional vai diminuindo, uma vez que a intensidade da necessidade também vai diminuindo até ao ponto de saciedade, ponto a partir do qual a utilidade passa a ser negativa. No mercado, a utilidade marginal corresponde ao preço dos bens. O sacrifício do consumidor não é senão o preço que ele tem de pagar para adquirir uma unidade do bem.

Os desenvolvimentos dos marginalistas são a base do pensamento neoclássico ${ }^{5}$. De acordo com a teoria neoclássica da escolha, o consumo é um ato racional por excelência, no qual o consumidor gere o seu autointeresse. A teoria da escolha racional dos consumidores pressupõe que os consumidores têm as suas preferências bem definidas e, por isso, tentam satisfazê-las da forma mais eficiente possível (Samuelson \& Nordhaus, 1993). Apesar de ser difícil quantificar e medir a satisfação associada ao consumo, em 1881, Edgeworth mostrou que era possível ordenar os bens por ordem de preferência. Para tal, é necessário, por um lado, definir as várias combinações de bens que o consumidor é capaz de comprar e, por outro, ordenar as várias combinações possíveis, para selecionar aquela que o consumidor prefere.

A ordenação das preferências dos consumidores partilha quatro propriedades (Samuelson, 1938): a exaustividade, que refere que uma ordenação de preferências está completa se permitir ao consumidor ordenar todas as combinações possíveis de bens e serviços; a transitividade, que refere que se o bem A é preferível ao bem $\mathrm{B}$ e o bem

\footnotetext{
${ }^{4} \mathrm{O}$ marginalismo é uma teoria positiva, que tem como principais figuras William Stanley Jevons (1835-82), Carl Menger (1840-1921) e Léon Walras (1834-1910). Apesar de Marshall não ser considerado um dos fundadores do marginalismo, foi o seu livro Princípios de Economia Política, que substituiu a teoria dominante de John Stuart Mill. A partir daqui a sua publicação passou a orientar o ensino de economia em Inglaterra e nos Estados Unidos. Os pressupostos desta teoria defendiam que os seres humanos agiam sempre de modo racional, isto é, em função do seu próprio interesse.

${ }^{5}$ As publicações de Jevons, Menger e Walras, tornaram-se o ponto de partida para a fundamentação da teoria neoclássica.
} 
B é preferível ao bem $\mathrm{C}$, então o bem A é preferível ao bem $\mathrm{C}$; a propriedade de quanto mais, melhor, que significa que se tudo o resto permanecer constante, maior quantidade de um bem é preferível a menor quantidade desse mesmo bem; e a taxa marginal de substituição decrescente, que significa que podendo optar-se por dois bens, à medida que se tem mais quantidade de um, a quantidade que se está disposto a prescindir do outro é cada vez menor. Verificando-se estas quatro propriedades, o consumidor pode ordenar as suas combinações e escolher aquela que maximiza a sua utilidade.

Através do conceito de utilidade, a teoria económica explica como os consumidores efetuam as suas escolhas de consumo, tendo em conta o seu rendimento disponível e o preço dos bens. A escolha do consumidor é, neste contexto, concebida como um problema de maximização da função utilidade, sujeita à restrição orçamental da família. Definida a combinação preferida e dados os preços dos bens e o seu rendimento, o consumidor maximiza a sua utilidade ao adquirir o cabaz que lhe proporciona maior satisfação.

Através desta teoria, é possível obter a relação entre o preço e a quantidade consumida - função procura -, a partir do processo de maximização da utilidade do consumidor. De uma forma geral, o consumo diminui à medida que o preço de um bem aumenta. Esta relação entre o preço e o consumo deve-se principalmente a dois efeitos: o efeito substituição, que nos diz que face ao aumento do preço de um bem, o consumidor irá procurar consumir um bem substituto; e $o$ efeito rendimento, segundo o qual, o aumento do preço de um bem (mantendose o rendimento) fará baixar o rendimento real e, por isso, o consumo de todos os bens.

De acordo com a teoria racional da escolha, o consumidor é um homo economicus que prefere sempre mais a menos, que não é saciável e cuja satisfação depende da quantidade dos bens consumidos. Nada é dito sobre a qualidade, pressupondo-se que os bens são homogéneos.

$\mathrm{Na}$ abordagem macroeconómica do consumo, trata-se o consumo sobretudo como o consumo das famílias e estabelece-se a sua relação com o rendimento e a poupança ${ }^{6}$. O consumo das famílias é a parte do

\footnotetext{
${ }^{6}$ Apesar de o consumo agregado se dividir no consumo privado e no consumo público, o conhecimento do consumo privado é essencial para compreender o crescimento dos países e dos ciclos económicos, uma vez que o consumo das famílias representa normalmente a maior parcela na despesa agregada ou no Produto Interno Bruto de um país. Em Portugal, o consumo das famílias representa cerca de $60 \%$ do PIB (Ramos, 2009). O Consumo Público consiste no consumo da Administração Pública, que consome bens e serviços necessários à sua atividade e cujos valores são regularmente inferiores aos do consumo privado.
} 


\section{Filipa Ramos Moreira}

rendimento disponível gasta em bens e serviços e a poupança é a parte do rendimento que não é consumida (Samuelson \& Nordhaus, 1993).

Nesta perspetiva, o principal fator económico que vai influenciar o consumo é o rendimento. Em 1936, Keynes mostrou que quando o rendimento aumentava, as despesas com o consumo também aumentavam. Este autor trouxe um ponto de rutura à teoria económica, uma vez que até aqui os economistas não consideravam a procura $\mathrm{e}$, consequentemente, o consumo, variáveis relevantes para a economia. O papel central cabia à produção ou à oferta, teorizada pela famosa "lei de Say" (formulada no início do século XIX pelo economista francês J. B. Say), segundo a qual toda a oferta cria a sua própria procura.

A relação entre o consumo e o rendimento é descrita através da função consumo, desenvolvida por Keynes em 1936. Este autor considerava que a taxa de juro não influenciava o consumo e que o consumo aumentava à medida que o rendimento também aumentava. Deste modo, resumiu a determinação do consumo agregado na "lei psicológica fundamental" segundo a qual as variações no nível de rendimento disponível conduzem a variações no nível de consumo mas numa proporção menor e a uma proporção média decrescente, quando o rendimento aumenta ${ }^{7}$.

$\mathrm{Na}$ construção da função consumo inclui-se o consumo de todos os agentes, mas a propensão a consumir varia de agregado familiar para agregado familiar. Não é difícil perceber que os agregados familiares com rendimentos mais baixos apresentam valores para a propensão marginal a consumir mais elevados do que a média dos agentes. $\mathrm{O}$ património ou riqueza do agregado também interfere no valor da propensão média a consumir. Para o mesmo nível de rendimento um património mais elevado levará a um consumo mais elevado. A previsão sobre os rendimentos futuros de um indivíduo também contribui para as decisões de consumo. Se um indivíduo tomar conhecimento de que o seu rendimento vai aumentar, normalmente, aumenta o consumo no presente. $\mathrm{O}$ mesmo acontece com a antecipação dos preços. Se um indivíduo antecipa uma subida no nível geral dos preços é natural que altere as suas decisões de consumo aumentando de imediato o nível de despesa de consumo. Os gostos ou preferências também influenciam o consumo, uma vez que a maior preferência por determinado bem faz aumentar o seu consumo. Por fim, a maior ou menor facilidade de obtenção de crédito e

\footnotetext{
${ }^{7}$ Nesta análise da função consumo apenas se consideram as relações entre o consumo e o rendimento disponível. No entanto, são múltiplas as determinantes da evolução do consumo global na economia. As variáveis mais importantes são a repartição do consumo, o património ou riqueza, a antecipação dos rendimentos e dos preços e o recurso ao crédito ao consumo.
} 
as taxas de juro que os bancos praticam são fatores importantes na explicação da variação do consumo.

As famílias aplicam o seu rendimento no consumo de diversos bens e serviços ou num número de rubricas a que se chama Estrutura de Consumo. A Estrutura de Consumo permite estudar o grau de bem-estar ou o nível de vida de uma sociedade, o que faz com que o consumo seja muitas vezes referido como um indicador de bem-estar de uma população. Para estudar a Estrutura de Consumo é habitual dividir as despesas de consumo em categorias como alimentação, vestuário e calçado, habitação, transportes, lazer, entre outros.

De acordo com Engel existe uma relação entre os rendimentos das famílias e a respetiva Estrutura de Consumo, uma vez que, quanto menor for o rendimento de uma família, maior tenderá a ser a proporção dos seus rendimentos gasta em alimentação e menor será a proporção dos seus rendimentos gasta em saúde, cultura, lazer, habitação, entre outros fins. Assim, à medida que o rendimento das famílias aumenta, a proporção da despesa destinada à alimentação vai diminuindo, aumentando por sua vez o peso das despesas destinadas às outras categorias.

O consumo das famílias tem um papel fundamental na vida económica porque garante a continuidade do processo produtivo, ao escoar os produtos necessários à satisfação das necessidades dos consumidores, porque afeta a atividade produtiva das empresas, já que lhes permite saber quais os bens mais adquiridos pelas famílias dando, assim, informações importantes à produção, e porque altera os valores da sociedade, através, por exemplo, do consumo ético e responsável. $\mathrm{O}$ vínculo entre os processos de produção e o consumo está condicionado pela ação das leis económicas dos respetivos modos de produção. O consumo valida a oferta de bens por parte das empresas e representa, pela aplicação dos rendimentos, um mecanismo importante para os comportamentos agregados dos consumidores e dos vendedores (Ramos, 2009). No processo de consumo distingue-se o consumo final do consumo intermédio, conforme o consumo se concretize no ato de satisfazer diretamente e de forma imediata as necessidades ou desejos individuais ou coletivos, ou no ato de utilização dos bens ou serviços num novo processo de produção. No primeiro caso, o consumo pode implicar o desaparecimento de um produto, com maior ou menor rapidez, por destruição ou por transformação. No segundo caso, os bens são incorporados em novos produtos que virão a ser produzidos e consumidos posteriormente. O consumo pode ainda ser individual ou coletivo, consoante sirva para satisfazer necessidades individuais ou coletivas. $\mathrm{O}$ consumo individual de um bem ou serviço impede a sua utilização por outro em simultâneo. Trata-se de um processo de consumo final, em que 
os bens são consumidos de imediato. O consumo coletivo consiste no uso de bens e serviços coletivos, geralmente fornecidos pelo Estado, e utilizados e consumidos de uma forma duradoura.

Pode ainda distinguir-se o consumo quanto à sua necessidade. $\mathrm{O}$ consumo essencial satisfaz necessidades primárias, enquanto o consumo supérfluo satisfaz necessidades terciárias. O tempo é também um fator fundamental na classificação dos atos de consumo, uma vez que alguns bens são consumidos diariamente e, consequentemente, substituídos, e outros têm de ser conservados ou armazenados para utilização futura.

Os padrões de consumo variam de acordo com os hábitos, os costumes, os países e a sua cultura, a época do ano, os grupos ou a classe social a que pertencem os consumidores. Estas disparidades no consumo de bens explicam-se pelas diferenças de nível e estilo de vida, de utilização dos meios de lazer, entre outros. $\mathrm{O}$ consumo não tem, assim, apenas um significado económico. Sendo um fenómeno eminentemente social, que se desenvolve a partir de necessidades que são geradas e satisfeitas num contexto de interdependências entre vários agentes, enquadra-se em expectativas e interpretações sociais que fazem extravasar o consumo de uma mera função utilitária ou da análise micro e macroeconómica (Frade, 2007).

\section{O CONSUMO NA CONSTRUÇÃO DE IDENTIDADES E DE RELAÇÕES SOCIAIS}

Os progressos tecnológicos e industriais do início do século XX, que permitiram produzir a baixos custos e em larga escala, transformaram o processo de consumo, tornando-o mais rápido, mais fácil e multifacetado. Na sociedade de consumo, cujas bases remontam à ascensão da burguesia e à Revolução Industrial do século XVIII, os consumidores passaram a ter ao seu dispor uma ampla variedade de bens e serviços, oferecida por múltiplos formatos comerciais e garantida por uma pluralidade de formas de financiamento (Frade, 2007, p.35). A partir da década de 50 do século passado, em consequência da conjuntura económica favorável e do aumento do poder de compra das populações, devido à melhoria substancial do seu nível de vida, surge o consumo de massas nos países industrializados. De uma sociedade organizada em torno da produção, passa-se para uma sociedade em que os estilos de vida se orientam principalmente por comportamentos associados ao consumo de bens e serviços. A flexibilização no mercado de trabalho conduziu a uma redução do tempo de trabalho e a um aumento do tempo livre, tornando o lazer um tema central da sociedade contemporânea. O lazer acentuou a valorização do prazer e do hedonismo, criando novas rotinas na 
sociedade. Como a existência de tempo livre e os modos do lazer se começaram a afirmar cada vez mais como expressões de consumo, nasceu uma renovada oferta comercial para os conjugar. As transformações no consumo foram acompanhadas por mudanças registadas nos circuitos de distribuição: do comércio tradicional e de proximidade passou-se para o comércio dos centros comerciais e das grandes superfícies situadas nas periferias. Estes espaços são criados com uma nova filosofia, onde os horários alargados e uma maior variedade, enquadrados em espaços agradáveis em que o lazer tem um papel preponderante, permite a possibilidade do frequentador fazer ou não compras, tornando subjacente a ideia de liberdade e de comprar com agrado. Para além da área comercial, estes novos formatos são completados com áreas de restauração, cinemas, pistas de bowling e espaços de jogos, garantindo para toda a família entretenimento por largas horas. Como o espaço é amplo, existem grandes estacionamentos e o acesso é rápido e livre de obstáculos. Por isso, o espaço comercial é hoje comparado a um espaço de lazer, de convívio e de cultura (Frade, 2007, p. 37).

Em Portugal, assistiu-se a uma evolução rápida no crescimento destas grandes superfícies. De acordo com a Associação Portuguesa de Centros Comerciais (2009a, 2009b), o primeiro grande centro comercial surgiu em 1985, em Lisboa. Até então, o panorama nacional era marcado pelos pequenos centros comerciais e por algumas galerias de lojas junto dos supermercados. Passadas cerca de duas décadas, em 2007, existiam 100 centros comerciais abertos ao público, com uma área bruta de localização acumulada de 3,3 milhões de metros quadrados, que englobam mais de 8.500 comerciantes. Em 2007, esta associação contabilizou cerca de 500 milhões de visitas em todos os centros associados, o que significa que em média, cada português ia aproximadamente uma vez por semana aos shoppings ${ }^{8}$.

A modernização e sofisticação da envolvente comercial não se fez sentir apenas nos espaços físicos e tem procurado tirar proveito das vantagens que as novas tecnologias e sistemas de telecomunicações proporcionam. De acordo com os resultados do barómetro da Associação do Comércio Eletrónico de Portugal (2008), o comércio eletrónico é uma realidade incontornável e em franca expansão no mercado português ${ }^{9}$. Em

\footnotetext{
${ }^{8}$ De acordo com um estudo do Portugal Retail Overview (2008), à semelhança do sucedido no ano de 2007, o ano de 2008 foi um ano bastante positivo para o setor de Centros Comerciais em Portugal. Em 2008 assistiu-se a um aumento da área bruta de localização na ordem dos $13 \%$, com a abertura de cerca de $280.000 \mathrm{~m} 2$ divididos por 9 novos centros comerciais. Segundo este estudo, existem projetos para o desenvolvimento e a implementação de mais 65 centros comerciais até final de 2011 .

${ }^{9}$ Este estudo foi realizado pela Netsonda e pela Associação do Comércio Eletrónico em Portugal [ACEP], e tem por objetivo fundamental, avaliar a evolução e
} 


\section{Filipa Ramos Moreira}

2008, e face ao período homólogo de $2007,80 \%$ dos sites inquiridos registaram um aumento no volume de vendas, $58,5 \%$ registaram um aumento até $50 \%$ do número de clientes e $24,1 \%$ registaram um aumento superior a $50 \%$ da sua carteira de clientes. Relativamente ao investimento realizado nos sites, cerca de $44,8 \%$ aumentou esse investimento com o objetivo de responder mais adequadamente às solicitações crescentes dos clientes em particular e do mercado em geral. A revolução digital é mesmo uma das influências mais significativas no comportamento dos consumidores, que tenderá a expandir-se à medida que cada vez mais pessoas no mundo utilizarem a internet. A importância deste crescimento é muito relevante uma vez que as compras do comércio eletrónico são geralmente liquidadas através do cartão de crédito.

Toda esta modernização e sofisticação da oferta foram acompanhadas por um notável desenvolvimento do marketing e da publicidade que, através dos meios de comunicação (televisão, rádio, revistas, internet), criaram novas necessidades de consumo e asseguraram a venda de novos produtos. $\mathrm{O}$ marketing e a publicidade tiveram um papel importante na promoção do consumo, divulgando-o como uma ação legítima, rica em significados e cheia de promessas imaculadas. Uma série de aspirações positivas individuais e de imagens de autorrealização têm sido associadas à aquisição e à utilização privada de bens e serviços - felicidade, sociabilidade, juventude, prazer, amizade, erotismo, e assim por diante (Sassatelli, 2008). As técnicas de marketing já não se limitam a campanhas de preços, procurando outras formas mais sofisticadas de promoção de vendas, através do apelo aos valores privilegiados pelos consumidores e ao relevo dado ao conhecimento do ser humano.

Os meios de comunicação foram responsáveis pelo processo de relativa uniformização dos desejos de consumo, devido à divulgação das mercadorias consideradas consensualmente como objetos de desejo. Atualmente, todas as classes desejam as mesmas coisas: casa, carros, viagens, computadores, telemóveis e bens culturais e de lazer. Ao mesmo tempo que as classes menos favorecidas passaram a ter os mesmos desejos das classes mais favorecidas, nestas últimas passou a ser bem visto misturar marcas caras com marcas baratas. Verifica-se, assim, uma desregulamentação dos comportamentos de consumo, através de um

desenvolvimento do Comércio Eletrónico em Portugal na perspetiva da oferta, assim como a confiança e expectativas dos seus protagonistas. $\mathrm{O}$ alvo definido para o estudo realizado foram algumas das mais representativas empresas associadas da ACEP. Importa destacar a variedade de setores representados pelas empresas participantes neste Barómetro, assim como, o facto de as mesmas representarem em conjunto uma considerável fatia da totalidade do volume de negócios do comércio eletrónico em Portugal. 
processo de bipolarização das compras, onde os extremos vivem em conjunto $^{10}$. Há um novo consumidor, que é flexível, imprevisível e sem coordenadas (Lipovetsky, 2007).

$\mathrm{Na}$ sociedade atual, o ato de consumir reflete e encoraja os mecanismos de reprodução social, ou seja, a forma de perpetuação das classes ou estratos sociais. Veblen (1965) na sua obra "A teoria da classe ociosa" mostra que o consumo é um ato que consiste na afirmação do estatuto. Entende o consumo como uma forma de ostentação, onde não existem objetos desejáveis por si mesmo, mas uma pressão contínua em termos de prestígio e reconhecimento, de estatuto e de integração social. O produto não se compra pelo seu valor mas pelo que ele representa. Este consumo não é exclusivo das classes mais altas, mas estas servem-se deste meio para exporem socialmente a sua riqueza e ociosidade (sinais exteriores de riqueza) (Mowen \& Minor, 2006, p. 328). Já em 1890, Tarde reconhecia que existia uma veneração da novidade, associando o processo de moda à dinâmica da imitação entre as classes sociais. Baudrillard (2008) considerou que "o consumo surge como conduta ativa e coletiva, como coação e moral, como instituição. Compõe todo um sistema de valores, com tudo o que este termo implica enquanto função de integração do grupo e de controlo social" (p. 95). Braudillard (2001), refere ainda que se comunica através dos objeto, uma vez que o objeto representa um papel que frusta a sua funcionalidade mais simples (p.13). Frade (2007) completou ao referir que "os atos de consumo contribuem para a manutenção de relações sociais, não só porque permitem categorizar os individuos na estrutura social, mas também porque, de um modo mais direto, possibilitam a participação em atividades sociais" (p. 41).

As pessoas submetem, consciente ou inconscientemente, as suas ações aos ditames sociais. Certamente que dispõem de uma certa margem de escolha, mas os seus gostos e preferências são determinados em grande parte pelo meio e grupo social onde se inserem. Para Bourdieu (2007), os indivíduos são determinados socialmente. Bordieu (1983), através do conceito de habitus, um sistema de disposições duráveis e transponíveis que, integrando todas as experiências passadas, funciona como uma matriz de perceções, de apreciações e de ações, e torna possível a realização de tarefas diferenciadas, mostra que os indivíduos têm gostos e preferências que aos seus olhos parecem ser os mais naturais possíveis, mas que na realidade são o resultado de padrões comportamentais

\footnotetext{
${ }^{10}$ A principal razão para esta imprevisibilidade do consumidor deve-se, por um lado, ao aumento do conceito de low-cost e, por outro, ao crescimento do mercado de luxo desde a década de 90 .
} 


\section{Filipa Ramos Moreira}

interiorizados que o indivíduo recebeu do meio social em que está inserido.

A aquisição, posse e exibição (ou ocultação) de bens representa uma das formas de exprimir status social, que se faz de forma diferente consoante o estrato ou classe social a que o indivíduo pertença. Pelo poder simbólico de comunicar status que o ato de consumo adquiriu, a pertença ou aspiração a um estrato ou classe social constituem imperativos que moldam as decisões de consumo dos indivíduos e dos grupos.

Baudrillard (2008) defende que o processo de consumo deve ser visto como um processo de significação e de comunicação, mas também como um processo de classificação e diferenciação social (p. 66). A lógica paradoxal de apropriação dos símbolos em determinados grupos socioculturais estabelece-se através de uma relação dialética entre o desejo de se tornar padrão (obedecendo a um código ao adquirir o mesmo objeto) e o de se diferenciar (procura da individualidade através de um objeto que seja considerado simbolicamente superior). De acordo com Baudrillard (2008), o ato de consumir é um ato eminentemente simbólico porque o consumidor não compra um bem unicamente para satisfazer uma necessidade, mas para obter um símbolo que afirma o seu vínculo a um determinado grupo (ou classe) social que lhe serve de referência ou que o demarca do mesmo por referência a um grupo de estatuto superior. As pessoas consomem não apenas para satisfazer as necessidades básicas, mas também para ter acesso ao poder e ao prestígio que determinados bens representam e para, desse modo, compensar problemas de personalidade individual, tal como 1a autoestima. Na sociedade atual, o consumo é uma das principais formas de reprodução social e de diferenciação.

A aquisição de determinados objetos de consumo comporta uma dimensão simbólica que permite aos indivíduos expressar as suas preferências, atitudes e valores para si próprios (função de autodefinição) e para os outros (função de comunicação) (Frade, Lopes, Nogueira, Magalhães \& Brinca, 2006, p. 216). Além de motivos individuais para consumir, os motivos sociais desempenham um papel importante, como as comparações sociais, resultando em desejos de possuir aquilo que os outros têm. Assim, o papel que os bens desempenham atualmente vai muito além das tarefas que desempenham (Solomon, 2008, p. 34). Como o consumidor cria e mantém uma identidade através dos bens consumidos, os bens são valorizados não só pela sua alegada função primária, mas também pelo seu significado simbólico, socialmente determinado. O consumo faz parte do processo de comunicação social através do qual os indivíduos comunicam uns aos outros o seu status e a 
sua personalidade. Transformou-se no mais importante ideal de afirmação socioeconómica (Carvalho, 2009, p. 245). Featherstone (1995) afirma que "o consumo não deve ser compreendido apenas como consumo de valores de uso, de utilidades materiais, mas, primordialmente, com um consumo de símbolos" (pp. 33-34). A exploração destes símbolos pela publicidade e pelos meios de comunicação, associando aos produtos, imagens de beleza, de sedução, de autorrealização, de romance e de qualidade de vida, permite torná-los verdadeiras ilusões culturais, que fascinam o consumidor atual (Featherstone, 1995, p. 48). Como refere Bourdieu (1979), ao consumir tem-se em conta simultaneamente a funcionalidade e a culturalidade dos bens. A cultura dos bens remete-nos não só para um sistema de gosto, como também para um sistema de sinais de prestígio e de promoção social.

Sassatelli (2008), vai mais além da visão defendida por Baudrillard, segundo a qual na sociedade de consumo os consumidores consomem unicamente pelo simbolismo associado a esse consumo, para defender que na sociedade de consumo a escolha pode ser construída e praticada através de uma variedade de maneiras, algumas das quais internalizam valores diferentes do dinheiro e da quantidade e consideram o bem comum, as relações presentes e a participação cívica como elementos irredutíveis da satisfação dos consumidores.

Numa perspetiva algo diferente, Slater (2006) realça o poder criativo e libertador que o consumo pode representar para o indivíduo, face ao espartilho da sociedade (p. 176). Na mesma linha, Lipovetsky (2007) entende que no final do séc. XX se passou de uma sociedade de consumo, baseada na família, para uma sociedade de hiperconsumo, baseada no indivíduo ${ }^{11}$. De um consumidor subjugado pelas pressões do seu estatuto social, passou-se para um hiperconsumidor que procura emoções e bemestar, qualidade de vida e de saúde, marcas e autenticidade, imediatismo e comunicação. Como o consumo passa a ser efetuado em função do bemestar, torna-se mais sensitivo, emocional ou cultural, uma vez que o consumidor valoriza a qualidade sobre a quantidade. Ao comprar, o consumidor está a satisfazer os seus desejos e a gerir as suas emoções. À medida que a quantidade de bens que as pessoas têm aumenta, cresce o seu desejo de comprar algo que lhes traga valor hedónico (Solomon, 2008, p. 70). Como referem Mowen e Minor (2006), as classes mais altas tendem a comprar não apenas pela necessidade, mas também pelo prazer (p. 328). Os produtos passaram a refletir as necessidades emocionais dos

11 As pessoas passaram a ter atividades individualizadas, personalizadas, que passaram a gerir como querem. $\mathrm{O}$ individualismo passa a ser a chave principal para explicar o hiperconsumo. Por exemplo, o telefone, considerado um bem familiar, foi substituído pelo telemóvel, um bem individual que cada um gere à sua maneira. 


\section{Filipa Ramos Moreira}

consumidores, que procuram demonstrar o seu estilo de vida em tudo o que vestem, frequentam, conversam e usam. O conforto integra uma importante dimensão da satisfação sensorial. No entanto, o ideal de melhor não substitui a cultura do mais. Atualmente estas duas lógicas desenvolvem-se simultaneamente ${ }^{12}$.

Featherstone (1995) argumenta que "a sociedade de consumo se tornou essencialmente cultural, na medida em que a vida social fica desregulada e as relações sociais se tornam mais variáveis e menos estruturadas por normas estáveis" (p. 34). A pluralidade de consumidores é considerada através de um processo governado pelo jogo da imagem, do estilo, do desejo e dos símbolos, que lhes atribui modos de vida de acordo com os critérios de mercado.

Atualmente, é dada aos indivíduos a possibilidade de recomporem a sua própria identidade pela alteração dos seus padrões de consumo. Campbell (1995) relatou que "qualquer pessoa pode ser quem ela quiser, pois o sistema hierárquico fixo dos grupos de status social deu lugar a um sistema aberto em que cada indivíduo é livre e autoconsciente para escolher qualquer um dos múltiplos estilos de vida disponíveis" (p. 112).

O consumo desempenha, por conseguinte, várias funções. Por um lado, permite aos indivíduos satisfazer necessidades e obter prazer (Frade, 2005). Por outro lado, permite criar novas identidades e tirar partido de oportunidades emergentes de participação social. Por fim, passa a ser um instrumento de afirmação individual, reabilitando o "direito" à escolha individual, mas sob uma ótica relativista e não puramente utilitária (Frade, 2007, p. 42). O crédito, por permitir aos indivíduos comprar bens e serviços mais sofisticados e onerosos, e mediatizar os tempos de consumo, é um fator que contribui para a obtenção destas diferentes funções ${ }^{13}$. Embora a idade, o estatuto profissional e a fase do ciclo de vida sejam fatores objetivos e discriminatórios que influenciam o rendimento disponível e, consequentemente, o poder de compra dos indivíduos, estes têm a possibilidade de aceder a bens ou serviços que não são os correlativos à sua posição de classe, devido ao recurso ao crédito e ao modo de pagamento em prestações. Como refere Baudrillard (2008), o crédito desempenha um importante papel "sob a cor de gratificação e

\footnotetext{
${ }^{12}$ Verifica-se atualmente uma desmultiplicação dos serviços e abundância de bens, a comunicação em tempo real, o crescimento vertiginoso do número de páginas pessoais e de sites virtuais, entre outros.

${ }^{13}$ Crédito deriva das palavras credere, confiança e creditum, uma coisa confiada de boa fé. É a operação pela qual um banco põe determinada soma à disposição do beneficiário, com a promessa de este lhe pagar os juros convencionados e de the restituir, na data fixada para reembolso, a importância correspondente à que havia sido emprestada (Dicionários Editora, 2006, p. 456).
} 
facilidade de acesso à abundância, de mentalidade hedonista e de liberdade dos velhos tabus da poupança" (p. 96).

$\mathrm{Na}$ sociedade em que vivemos ter dinheiro para consumir significa sucesso, liberdade, segurança, reconhecimento e bem-estar. De acordo com Belk (1999), citado por Earl e Kemp (1999), o dinheiro é visto como uma forma de nos sentirmos poderosos, bonitos, inteligentes e talentosos. Pelo contrário, não ter dinheiro é sinónimo de fracasso individual e falta de caráter. Para além disso, a situação financeira também é responsável pela indução de estados emocionais negativos, nomeadamente a ansiedade, inveja, culpa, depressão, pânico, medo e insegurança. Deste modo, o crédito passou a ser avaliado na sociedade de forma positiva, passando a ser aceite como parte integrante da sociedade de consumo, uma vez que permite a obtenção imediata de um conjunto de bens e serviços. Já Keynes em 1936 referia seis motivos que justificavam o crédito: o prazer, a extravagância, a miopia, o erro de cálculo, a ostentação e a generosidade. As sociedades tornaram-se incrivelmente mais materialistas e consumistas, e esta concorrência aumentou claramente os gastos dos indivíduos e a sua tendência para financiar o consumo através dos empréstimos.

Esta tendência tornou-se ainda maior para o grupo de pessoas com um nível de rendimento abaixo do seu grupo de referência social. A necessidade de representar uma imagem e um estilo de vida semelhante ao desse grupo levou ao incremento da procura de crédito sem a ideia clara do que isso envolve. Quando o rendimento não permitia a compra de símbolos relevantes, uma das opções era utilizar o crédito para os obter.

\section{O CRÉDITO NO FINANCIAMENTO DO CONSUMO}

O crédito ao consumo, através das instituições de crédito, foi introduzido pela primeira vez em Chicago em 1878 (Beckman e Foster, 1969). No entanto, só no séc. XX, com a Revolução Industrial, é que se autonomizou. Com o advento do automóvel, a utilização do crédito começa a perder o seu duplo estigma de pobreza e prodigalidade (Frade, 2007, p. 51). Henry Ford foi exímio em utilizar o crédito para controlar a sua força de trabalho, estimular a produtividade e aumentar as vendas, que levou à sua legitimação mais cedo nos EUA do que na Europa. O grande debate americano, decorrido entre a criação da Russel Sage Foundation, em 1908, e o Consumer Credit Protection Act, em 1968, constituiu o processo mais extraordinário de legitimação social do crédito 


\section{Filipa Ramos Moreira}

ao consumo ${ }^{14}$ (Gelpi \& Julien-Labruyère, 2000, p. 140). Deste modo, as atitudes face ao crédito ao consumo mudaram dramaticamente.

Uma revolução nos hábitos de consumo e no modo de os financiar entrou em vigor no mercado americano. Multiplicaram-se as instituições de crédito e o financiamento destas permitiu a sobrevivência dos pequenos estabelecimentos artesanais. Numa tentativa de proteção desses estabelecimentos surgiram as associações cooperativas de crédito, ou bancos do povo, à imagem da Raiffeisen alemã ${ }^{15}$. O crédito democratizou-se, popularizou a sociedade de consumo e tornou as famílias americanas exemplos de sucesso e de felicidade (Frade, 2007, p. 51). O crédito ao consumo concedido pelo banco permitia às pessoas comprar bens de consumo duradouros para melhorar o seu estilo de vida.

A história do crédito ao consumo na Europa resultou de séculos de interdições e tabus. Em consequência, só no terceiro quartel do século XX é que o crédito ao consumo se desenvolveu verdadeiramente na Europa, baseado em duas mentalidades que divergiram no século XVI, a protestante e a católica. Nos anos da reconstrução europeia, depois da II Guerra Mundial, a importância dos negócios de crédito, com clientes privados, aumentou de forma significativa. $\mathrm{O}$ valor do crédito concedido era estabelecido consoante a disponibilidade do cliente em pagar as mensalidades. De modo a supervisionar a solvência do cliente, os mutuantes anunciavam o crédito concedido e recebiam, por seu lado, informações se o cliente pedisse outros créditos noutros bancos.

De uma maneira geral pode-se referir que, à exceção dos países do sul da Europa, a expansão da abertura dos mercados ao crédito na Europa teve início na década de sessenta, sendo que as diferenças que existem na sua generalização variaram de país para país, de acordo com fatores de enquadramento jurídico e de desenvolvimento económico, e com questões culturais e religiosas (Marques, Neves, Frade, Lobo, Pinto \& Cruz, 2000, pp. 3-4).

$\mathrm{O}$ ritmo de expansão do crédito ao consumo acelerou de forma explosiva no início da década de 80 com a "democratização" do crédito na Europa. Seguindo a liberalização da regulamentação do crédito ao consumo dos EUA, a maioria dos países europeus liberalizou as normas de crédito ao consumo, permitindo que os consumidores decidissem como e em que medida se endividar. $\mathrm{O}$ crédito tornou-se socialmente

14 No Título I da Lei de Proteção do Crédito ao Consumidor, em 1968, foi promulgado The Truth in Lending Act. Esta lei referia que "a estabilização económica seria melhorada e que a concorrência seria reforçada pelo uso informado de crédito resultante de uma consciência dos custos de crédito por parte dos consumidores".

${ }^{15}$ No caso particular da agricultura foi Friederich Wilhelm Raiffeisen o primeiro fundador de uma sociedade de crédito. 
aceitável e as pessoas passaram a confiar mais em pedir dinheiro emprestado. A abertura ao mercado de crédito ao consumo conduziu a uma intensa concorrência entre os fornecedores deste produto altamente rentável, levando-os a anunciar e a estruturar os seus produtos de uma forma que lhes permitisse obter elevados proveitos (Kilborn, 2005, p. 16).

O Reino Unido foi o primeiro país europeu a seguir o exemplo americano. As proibições morais desapareceram gradualmente e as pessoas de todas as classes começaram a reconhecer a necessidade essencial do crédito ao consumo e as suas vantagens em termos de evolução económica e social. Para tal, foram desenvolvidas as mesmas técnicas e o mesmo equilíbrio legislativo baseado num grande liberalismo económico e contrabalançado pela forte influência dos movimentos de proteção ao consumidor (Gelpi e Julien-Labruyère, 2000, p. 196).

Em França foram os ideais socialistas associados a Saint-Simon que conduziram à criação de sociedades bancárias (Gelpi e Julien-Labruyère, 2000). A opinião pública, na sua maioria, condenava os empréstimos monetários, de qualquer tipo. Baudrillard considerava o crédito como uma espécie de imposto sobre a pobreza cobrado pelos monopólios financeiros e que corrompia as camadas superiores do proletariado. Apesar deste terreno ideologicamente desfavorável e com uma geração de atraso relativamente aos Estados Unidos, o crédito ao consumo desenvolveu-se, baseado nas necessidades mais imediatas da sociedade moderna e na maior diversidade de produtos. Contudo, muitos dos velhos preconceitos mantiveram fortes raízes até ao final da década de oitenta do século XX.

A Portugal, o crédito só chegou já na década de noventa, apoiado na desregulamentação do sistema bancário nacional, na liberalização e descida das taxas de juro, na eliminação de políticas de limites de crédito e no surgimento de novos instrumentos de crédito, em consequência do fim da reserva de iniciativa pública no setor bancário em 1984 (DecretoLei n. $^{\circ}$ 51/84, de 11 de fevereiro), que fez parte de um movimento internacional generalizado de desregulamentação dos mercados financeiros (Frade, 2007, p. 52). O aumento da concorrência entre os bancos também possibilitou o acesso ao crédito a um conjunto mais vasto de famílias, conduzindo ao longo da década de noventa a um rápido aumento do seu endividamento (Farinha, 2007, p. 141).

Frade (2007), referiu que "a par das clássicas instituições bancárias (também elas em notável transformação) surgem outras instituições que concedem crédito ao consumo, e que concorrem diretamente com os bancos na concessão de crédito aos particulares, nomeadamente, junto dos estabelecimentos comerciais, como é o caso em Portugal, das Sociedades Financeiras para Aquisições a Crédito [SFAC]" (p. 38). 
As SFAC surgiram no espaço financeiro português na década de oitenta, tendo recebido a sua primeira regulamentação legal através do Decreto-Lei n. ${ }^{\circ}$ 49/89, de 22 de fevereiro. Funcionalmente, elas permitem financiar a aquisição a crédito de bens de consumo e serviços, dominando atualmente cerca de 50\% deste mercado (Frade, 2007).

O baixo nível de endividamento das famílias portuguesas, as campanhas publicitárias que mostravam as vantagens do crédito ao consumo, o processo de adesão à União Económica e Monetária e a entrada na zona euro, que implicaram uma redução drástica da taxa de inflação e das taxas de juro, e a existência de menores custos de transação devido ao rápido desenvolvimento tecnológico, contribuiu igualmente para o crescimento exponencial do mercado de crédito, colidindo com valores tradicionais contraditórios e bem enraizados na sociedade (Marques et al, 2000; p.22). Por fim, a alteração considerável no padrão de despesas nas últimas décadas em Portugal também contribuiu para este crescimento. De acordo com o Inquérito às Despesas das Famílias 2005/2006 (Instituto Nacional de Estatística [INE], 2008), a estrutura da despesa das famílias evidencia o ganho da importância relativa de grupos de produtos e serviços na área da hotelaria e restauração, saúde, lazer, distração e cultura e ensino a par da diminuição da importância relativa das despesas em vestuário e calçado, móveis, artigos de decoração e equipamentos domésticos, transportes, bebidas alcoólicas e tabaco, alimentação e comunicações. Em 2005/06 acentua-se a importância relativa das despesas com habitação que passaram, desde 2000, a constituir a principal afetação das despesas familiares, refletindo também o maior aumento proporcional no total da despesa. Pelo contrário, manteve-se a tendência de perda de peso da despesa em produtos alimentares na composição das despesas familiares. Em duas décadas e meia, estas despesas viram baixar para cerca de metade a sua importância relativa. Este novo contexto proporcionou uma intensificação das relações das famílias com o sistema bancário, quer em termos de produtos disponíveis, quer na frequência da sua utilização (Banco de Portugal, 2010, p. 145).

De acordo com a Figura 1, e no que diz respeito à procura de crédito, o número de portugueses que recorreu ao crédito ao consumo aumentou sistematicamente desde 2001 até 2005, duplicando o número de indivíduos que recorreram a este tipo de crédito neste período. Em 2001, cerca de $12 \%$ do total dos indivíduos que possuía conta bancária detinha um crédito ao consumo e, em 2005, este valor era de cerca de 24,5\%, uma vez que neste ano este indicador cresceu $54,1 \%$ relativamente ao mesmo período do ano anterior, registando, assim, a maior taxa de variação anual neste período. 
Com a crise financeira mundial, tem-se assistido a uma quebra nos valores apresentados por este indicador, que revela que, em 2008, um em cada cinco possuidores de conta bancária recorre a este tipo de crédito, abrangendo cerca de $22,1 \%$ desta população. Em 2009, este valor diminuiu para cerca de $20 \%$ e em outubro de 2010 situava-se em cerca de 19,6\%, com 1413 mil indivíduos residentes no Continente com 15 ou mais anos que possuem conta bancária a recorrer ao crédito bancário para aquisição de bens e serviços (Marktest, 2011). Em 2010 foram celebrados, em média, 121617 contratos mensalmente, o que corresponde a um montante médio mensal de crédito de cerca de 458 milhões de euros. Estes valores representam um decréscimo de 1,1\% na média mensal de contratos celebrados entre as instituições de crédito e os seus clientes e um aumento de $1,3 \%$ no montante médio mensal de crédito concedido (Banco de Portugal, 2011b, p.130).

$\mathrm{O}$ inquérito aos bancos sobre o mercado de crédito, realizado em janeiro de 2011, pelo Banco de Portugal, realça relativamente à procura de crédito ao consumo, que três instituições indicaram que diminuiu ligeiramente face ao trimestre anterior, enquanto as restantes se dividem entre a diminuição considerável e a ausência de alterações. A diminuição da confiança dos consumidores e a retração das despesas de consumo de bens duradouros terão sido, segundo a amostra, os principais fatores conducentes a esta evolução (Banco de Portugal, 2011a, p. 2).

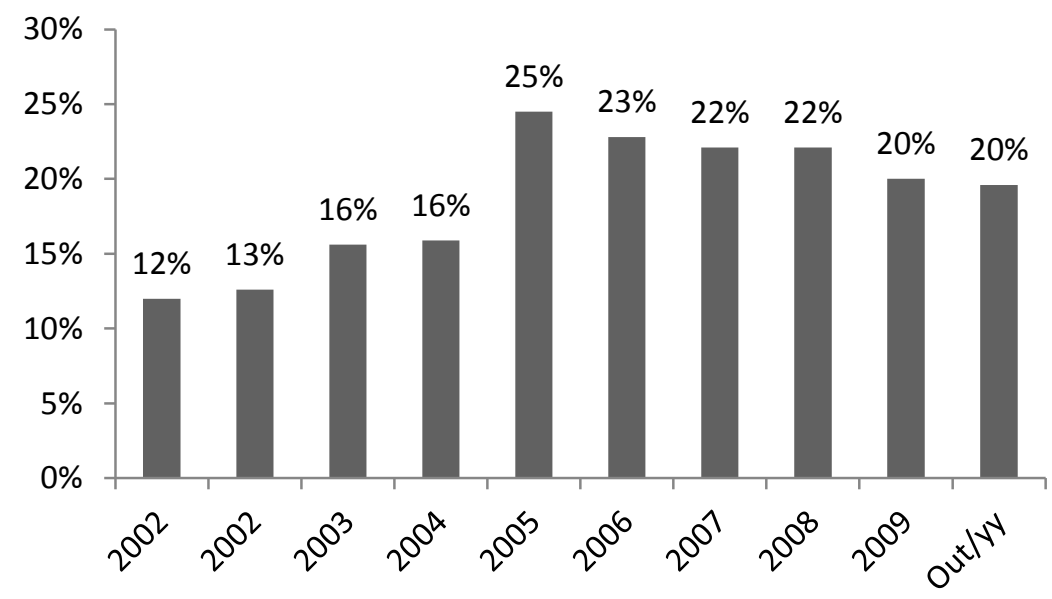

Figura 1: Penetração do crédito ao consumo Fonte: Marktest, 2011a 
Em consequência do aumento rápido da concessão de crédito na última década, a taxa de endividamento em Portugal aumentou significativamente, sendo atualmente uma das mais altas da Zona Euro (Banco de Portugal, 2010, p. 43). Esta taxa cresceu de forma continuada em Portugal desde a década de noventa. Se no início da década representava cerca de $20 \%$ do rendimento disponível, passou para $85 \%$ no final de 2000, ultrapassou os $100 \%$ em 2003 e atingiu cerca de $138 \%$ no final de 2009 (conforme Figura 6).

Apesar do aumento do endividamento dos particulares ter sido comum à maioria dos países europeus durante os últimos anos, o nível atingido em Portugal só é superado, no contexto da área do euro, pelo registado na Dinamarca, nos Países Baixos, na Irlanda e no Reino Unido, mantendo-se um dos mais elevados da Zona Euro (Banco de Portugal, 2009; Banco de Portugal, 2010, p. 43)

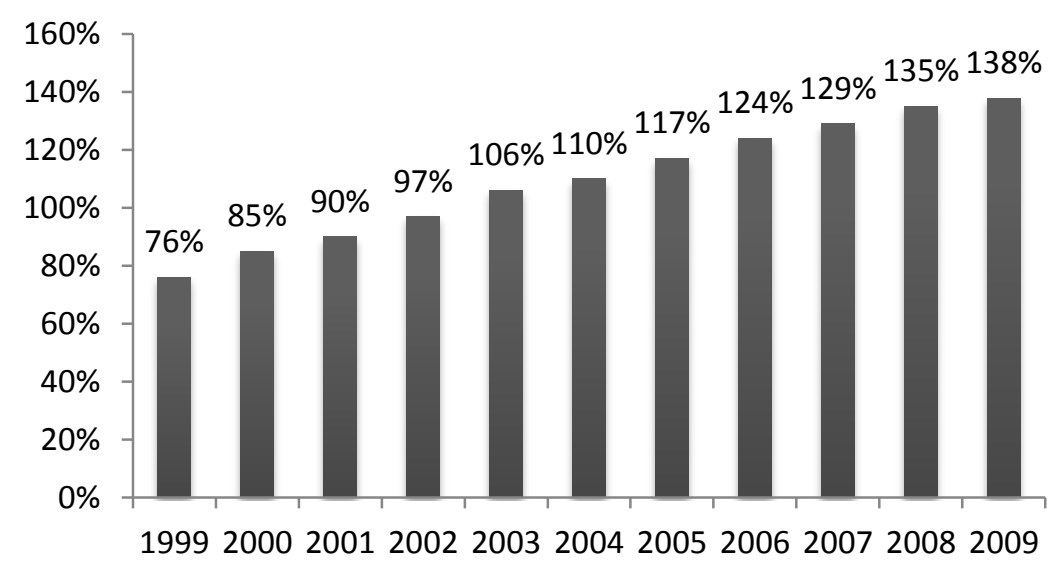

Figura 2: Taxa de Endividamento em Portugal (\% do rendimento disponível) Fonte: Banco de Portugal, 2010; INE, 2010.

Atualmente o crédito democratizou-se, tornou-se uma componente normal do orçamento familiar, permitindo a muitas famílias antecipar regularmente uma percentagem variável do seu rendimento futuro. Tornou-se, nas sociedades ocidentais, uma constante na primeira fase de vida das famílias, em que estas procedem à aquisição de equipamento (casa, automóvel, eletrodomésticos, mobiliário) indispensável à sua condição de vida familiar e económica. $\mathrm{O}$ crédito deixou de estar associado apenas ao exercício de uma atividade profissional ou de servir sobretudo para fazer face a circunstâncias excecionais de falta de 
liquidez. Com a generalização do crédito pessoal, o crédito ao consumo é utilizado na compra de todo o tipo de bens (Marques \& Frade, 2003, p. 29).

\section{CONCLUSÃO}

A reflexão crítica mostrou que, na sociedade contemporânea, o consumo desempenha várias funções como seja as de permitir satisfazer necessidades individuais e coletivas, criar novas identidades, sustentar a afirmação individual no espaço coletivo e conduzir à obtenção de prazer. $\mathrm{O}$ crédito, por possibilitar aos indivíduos comprar bens e serviços mais sofisticados e onerosos, e assim mediatizar os tempos de consumo, tem permitido a plena concretização destas funções. Por isso, a sua conotação social e moral tornou-se mais positiva, passando a ser aceite como parte integrante da sociedade de consumo e modo corrente de gerir o orçamento familiar. As sociedades tornaram-se mais materialistas e hedonistas, o que propiciou o aumento dos gastos dos indivíduos e do respetivo financiamento por meio do crédito. A necessidade de representar uma imagem e um estilo de vida semelhante ao dos grupos de referência social levou ao incremento da procura de crédito sem a ideia clara dos riscos que tal processo envolve. A crise financeira que se vive atualmente pode ser explicada em parte pelo facto de os meios financeiros limitados que a maioria das famílias dispõem as obrigarem a recorrer ao crédito para obtenção de bens que supram necessidades essenciais e, simultaneamente, permitam exibir alguns sinais de status.

O crédito, como financiador do consumo na sociedade atual teve, como se disse, uma expansão considerável nas últimas décadas, visível no aumento exponencial da taxa de endividamento das famílias. Em Portugal, esse aumento do endividamento iniciou-se na década de noventa, fazendo com que a taxa de endividamento nacional se tornasse uma das mais elevadas da União Europeia. O crédito democratizou-se, tornando-se, nas sociedades ocidentais, uma constante na primeira fase de vida das famílias, indispensável à sua condição de vida familiar e económica, e deixando de estar associado apenas ao exercício de uma atividade profissional ou de servir sobretudo para fazer face a circunstâncias excecionais de falta de liquidez. 


\section{REFERÊNCIAS BIBLIOGRÁFICAS}

ASSOCIAÇÃO DO COMÉRCIO ELECTRÓNICO DE PORTUGAL (2008). Barómetro Trimestral do Comércio Electrónico em Portugal. NETSONDA research group. Acedido a 12 de outubro de 2009, em:<http://www.netsonda.pt/xms/files/Estudos/netsonda_acep_12.p df

ASSOCIAÇÃO PORTUGUESA DE CENTROS COMERCIAIS. (2009a). Shopping, 68, maio de 2009.

ASSOCIAÇÃO PORTUGUESA DE CENTROS COMERCIAIS. (2009b). Relatório do Anuário 2008. Acedido a 24 de outubro de 2009, em:<http://www.apcc.pt/centros/Relatorio2008.pdf

BANCO DE PORTUGAL (2009). Relatório de Estabilidade Financeira|2008. Departamento de estudos económicos, Lisboa.

BANCO DE PORTUGAL (2010). Relatório de Estabilidade Financeira|novembro de 2010. Departamento de estudos económicos, Lisboa.

BANCO DE PORTUGAL (2011a). Inquérito aos bancos sobre o mercado de crédito. Departamento de estudos económicos, Lisboa.

BANCO DE PORTUGAL (2011b). Relatório de supervisão comportamental 2010. Departamento de Supervisão Comportamental, Lisboa.

BAUDRILlard, J. (2001). Palavras de ordem. Porto: Campo das Letras.

BAUDRILLARD, J. (2008). A sociedade de consumo. Lisboa: Edições 70.

BECKMAN, T.N. \& FOSTER. (1969). Credit and Collections. New York: Mcgraw-Hill Book Company.

BOURDIEU, PIERRE. (1979). La Distinction - critique sociale du jugement. Paris: Editions de Minuit.

BOURDIEU, PIERRE (1983). Questões de sociologia. Rio de Janeiro: Marco Zero.

BOURDIEU, PIERRE (2007). O poder simbólico. Rio de Janeiro: Editora Bertrand Brasil.

CAMPBELL, C. (1995), The Sociology of Consumption, Acknowledging Consumption. London: Routledge.

CARVALHO, J. E. (2009). Neuroeconomia - Ensaio sobre a sociobiologia do comportamento. Lisboa: Edições Sílabo.

DICIONÁRIOS EDITORA (2006). Dicionários de Língua Portuguesa. Porto: Porto Editora. 
EARL, P. \& KEMP, S. (1999). The elgar companion to consumer research and economic psychology. Massachusetts: Edward Elgar Publishing Limited.

FARINHA, L. (2007). O endividamento das famílias portuguesas: evidência recente com base nos resultados do IPEF 2006-2007. Banco de Portugal, Relatório de Estabilidade Financeira - 2007, 141-165.

FEATHERSTONE, M. (1995). Cultura de consumo e pós-modernismo. São Paulo: Studio Nobel.

FRADE, C. (2005), Medição do sobreendividamento: uma solução célere e de proximidade, Themis, Ano VI, 11.

FRADE, C. (2007). A regulação do sobreendividamento (Tese de Doutoramento), Coimbra: FEUC.

FRADE, C. LOPES, C., NOGUEIRA, C., MAGALHÃES, S. \& BRINCA, P. (2006). Desemprego e sobreedividamento das famílias: contornos de uma 'ligação perigosa'. Acedido a 20 de setembro de 2009], em: <www.oec.fe.uc.pt.

GELPI \& JULIEN-LABRUYÉRE. (2000). História do Crédito ao Consumo - doutrinas e práticas. Cascais: Principia.

INSTITUTO NACIONAL DE ESTATISTICA [INE] (2008). Inquérito às despesas das famílias 2005/2006, Lisboa: INE.

KILBORN, J. (2005). Behavioral Economics, Overindebtedness and Comparative Consumer Bankruptcy; Journal of European Law. 22, 13-46.

LIPOVETSKY, G. (2007), A felicidade Paradoxal. Ensaio sobre a sociedade do hiperconsumo. Lisboa: Edições 70

LOBO, F. (1998). Crédito ao consumo e restrições de liquidez: uma aplicação à economia portuguesa (Dissertação de Mestrado). Coimbra: FEUC.

MARKTEST (2011). Crédito ao consume tende a abrandar. Acedido a 23 de janeiro de 2011, em: <http://www.marktest.com/wap/a/n/id 16a3.aspx.

MARQUES, M. M.; NEVES, V.; FRADE, C.; LOBO, F.;PINTO, P.; \& CRUZ, C. (2000), O Endividamento dos Consumidores. Coimbra: Almedina.

MARQUES, M.M. \& FRADE, C (2003). Uma sociedade aberta ao crédito. Subjudice, 24, 27-34.

MOWEN, J. \& MINOR, M. (2006). Comportamento do Consumidor ( $3^{\circ}$ ed.). São Paulo: Prentice Hall.

RAMOS, P. (2009). Comportamento do consumo das famílias. Acedido a 16 de setembro de 2009, em: <http://www4.fe.uc.pt/jasa/macroeconomia_6t.pdf. 
SAMUELSON, P \& NORDHAUS, W. D. (1993). Economia. Portugal: Mcgraw-Hill

SAMUELSON, P. (1938). A Note on the Pure Theory of Consumers' Behaviour. Economica. 5, 61-71.

SASSATELLI, R. (2008): Representing Consumers: Contesting Claims and Agendas. Acedido a 27 de janeiro de 2011, em: <http://www.sociol.unimi.it/docenti/sassatelli/Articoli\%20pdf/SASS ATELLI\%20-\%20BETTER\%20THAN\%20SHOPPING.pdf.

SLATER, D. (2006), The Sociology of Consumption and Lifestyle. In CALHOUN, ROJEK \& TURNER, The SAGE Handbook of Sociology (pp. 147-187), London: Sage.

SOLOMON, M. R. (2008). O comportamento do consumidor comprando, possuindo e sendo. Porto Alegre: Bookman.

PORTUGAL RETAIL OVERVIEW (2008). Portugal Retail Overview 2008 - EDIÇÃO MAPIC. Acedido a 27 de outubro de 2009, em: $<$ http://www.joneslanglasalle.pt/Portugal/PT-

PT/Pages/ResearchDetails.aspx?ItemID $=1390$

VEBLEN, T. (1965). A Teoria da Classe Ociosa. S. Paulo: Pioneira Editora 